\title{
CCRC Common Facility Spatial Structure: A study by Space Syntax
}

\author{
Lin Bai*, Satoshi Nasu \\ Department of Architecture, \\ School of Environment and Society, \\ Tokyo Institute of Technology, Japan \\ bai.l.ac@m.titech.ac.jp
}

\begin{abstract}
Spatial structure of 56 CCRCs(Continue Care Retirement Committee) which are mainly selected from AIA contest project are analyzed by using space syntax theory. Based on the result of common facility allocation and spatial centrality, three common facility allocation types and six route space integration models are defined. While the analysis shows the central allocation with route connected to a common facility being the highest integration place is the predominant spatial structure of common facility in US CCRCs, the combination of each common facility allocation type and route space integration models provide the fashion of common facility spatial structure in US CCRCs today. Keywords: CCRC, common facility, common space, space syntax.

eISSN 2514-751X @ 2017 The Authors. Published for AMER ABRA by e-International Publishing House, Ltd., UK. This is an open-access article under the CC BY-NC-ND license (http://creativecommons.org/licenses/by-ncnd/4.0/). Peer-review under responsibility of AMER (Association of Malaysian Environment-Behaviour Researchers), ABRA (Association of Behavioural Researchers on Asians) and cE-Bs (Centre for EnvironmentBehaviour Studies), Faculty of Architecture, Planning \& Surveying, Universiti Teknologi MARA, Malaysia.

https://doi.org/10.21834/aje-bs.v2i5.203
\end{abstract}




\subsection{Introduction}

\section{Background and Research Purpose}

CCRC, Continuing Care Retirement Community, is one of most popular senior living facility which offers a broad spectrum of housing and healthcare selections from independent living to skilled nursing care in the US and Europe(Fujii,2015). With the accelerating evolution of aged society worldwide, CCRC has also attracted the attention of other countries and has been introduced in Asia. Especially in Japan, a work group to promote Japanese version of CCRC has been set up by the government, and there were more than ten prefectures started to build Japanese version of CCRC by the year of 2015(Mitsubishi, 2015).

Initially, the CCRC is designed to provide complete hardware and software facilities to extend the longevity of the elderly independent life, so that in addition to cultivating a variety of hobbies and skills, there are plenty programs to enhance residents' social life. One of the important features in CCRC is community function which aims to develop resident social participation. Therefore, the appropriate allocation of the common facility in CCRC is important.

This article explores spatial structure of common facilities in US CCRCs. Even there exists difference in lifestyle and social background between the US and other countries, because there are more than 100 years of history of CCRC in the US, the understanding of current and how the spatial structure of common facility is transited in the US can be as a reference for CCRC common space design in other countries.

For this purpose, 50 CCRCs opened from the year of 1990 to 2015 and published in American Institutes of Architects(AIA) "Design for Aging Review"(AIA,2014), and 6 CCRCs investigated by the author on-site are selected as research objects. The allocation and spatial structure of common facility which includes common building complex, community center facility, and clubhouse are analyzed by space syntax theory to depict current and its transition in recent 25 years.

\subsection{Literature Review}

The common space is a concern for elderly facility design. There are many studies done so far for elderly facility common space. However, most of the studies were focused on the impacts of common space to elderly social life. By the observation of resident environmental behavior or interview on resident daily activities, these studies demonstrated the necessity, the importance of common space in elderly facility to resident social life, and explored the way on effective common space plan design. The researches done by Sugihara(2000), Schafer(2015), Joseph(2007), Ayalon(2012), Yang(2012), and Lois(2006) are typical examples of these studies. By the investigation of supportiveness of physical features, the spatial distance and proximity, Sugihara(2000) concluded residents social support was positively associated with smaller spatial distances, and Schafer(2015) concluded that residents interpersonal contact and voluntary relationships was increased by physical space 
proximity. Further, by observation of physical environment experience, Lois(2006) developed a theoretical procedure to estimate environmental deficits which potentially influence the resident quality of life in the nursing home. Moreover, Ayalon(2012) found that social ties of CCRC residents can be classified according to dimensions of time and space, Yang(2012) catalogized the importance of space hierarchy to CCRC residents social activity, Joseph(2007) indicated the walk path design of CCRC residents was shaped by practical considerations of space distance and convenience. Murakami(2011) clarified the basic elements in both nursing home resident daily life and environment, proposed a model in common space plan design.

However, these studies revealed the way of common space in affecting resident social and daily life in elderly facilities, the research results didn't provide systematic spatial characteristics of common space from the point of view of the spatial structure, and the research methods were mainly limited to environmental behavior observation and interview on resident daily activity. Although Joseph(2007) applied space syntax theory to develop walk path selection for 3 CCRCs, the study scope limited on outdoor path segment structure, and the research method largely relied on the depth, a spatial metric to measure the number of steps that need to be taken to get from one space to others, to evaluate the path accessibility, it did not provide comprehensive CCRC common space spatial structure characteristics like the integration and connection in CCRC each space unit.

\subsection{Methodology}

\subsection{Space Syntax Analysis Method}

Space syntax theory(SS) is applied in this study to provide the spatial structure of CCRC all space unit and common facility for specific. The theory itself has been getting extensive used since it was put forward and has been accepted as an appropriate mean in the spatial characteristics comparative study(Brown 1986). The theory provides a set of techniques for quantifying and analyzing the properties of architectural and space(Hillier B. 1996).

One of the techniques is axial line map(Behbahani 2014), it uses linear and nodal to describe a space. The axial line is defined as the longest straight line within the space boundary as shown in figure $1 \mathrm{~b}$. The intersection of a line describes the connections. By counting the intersections, the graph of connectivity is created(Figure 1c). This map represents the relationships of accessibility among all axial spaces. A common algorithm for producing such lines is called all-line approach, which creates the so-called all-line map by drawing all of the possible lines passing through this space(Turner, 2005).

Because this study aims to highlight spatial structure and accessibility of common facilities in CCRC, this method is utilized for the reason that it can represent the likely path of people movement, and is appropriate to quantify the route space characteristics of 
accessibility and selectivity(Behbahani 2014). In this article, this approach is implemented by a computer tool called DepthMap(Space Group UCL, 2014).

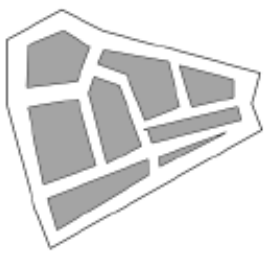

(a)

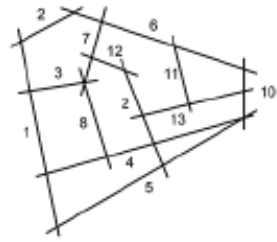

(c)

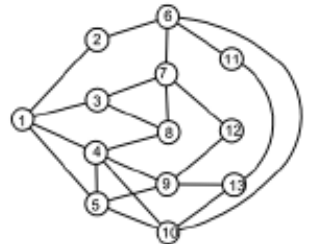

(b)

Figure 1: Space syntax axial map

(Source: Cited from Dettlaff 2014, P. 286)

Site plan of each selected CCRCs is scanned and converted to AutoCAD file, which is then imported to DepthMap tool to create the axial map. The spatial characteristics for each axial line within the map are calculated and based on the space unit boundary, the spatial characteristics of each space unit in CCRCs are averaged by one or multiple axial lines within it.

\subsection{Space Syntax Spatial Attributes}

By using DepthMap tool, the connectivity, mean depth, integration for each space unit in CCRC is calculated.

The connectivity metric is the number of links that connect to other space. A space with high connectivity owns more connections to others. In an axial map, the connectivity of space is the number of intersections across the line within it.

The depth is defined as change steps from the space to others, the step between immediate neighbors is one. In the axial map, a step is the change of direction from one line to another.

The integration metric describes the average depth of the space to all others. It is also regarded as the index of accessibility and selectivity, and is understood as an indicator of spatial structure centrality, and predict the pedestrian use of the space: the higher integration of the space, the greater centrality of this space within all space units, and the more popular it is within all others(Dettlaff, 2014). This metric is mainly used in this study to outline the transition of common facility spatial characteristics in different periods.

\subsection{Result and Analysis}




\subsection{Evaluation by Common Facility Allocation}

Based on geological allocation, the common facility is divided into three types.

Type 1 - Inner type. In this type, the common facility is inside other building or linked with others. For example, one part of the residential building may serve as a common facility, as the example shown in Table 1.

Type 2 - Edge type. In this type, the common facility is a dedicated building but is allocated on one side or edge area in CCRC, as the example shown in Table 1.

Type 3 - Central type. Same as type 2, but the common facility is situated in the central area or between two major parts of CCRC, for example, it may be located in the middle of residential and service areas as the example shown in Table 1.

Table 1: Common facility type in US CCRC

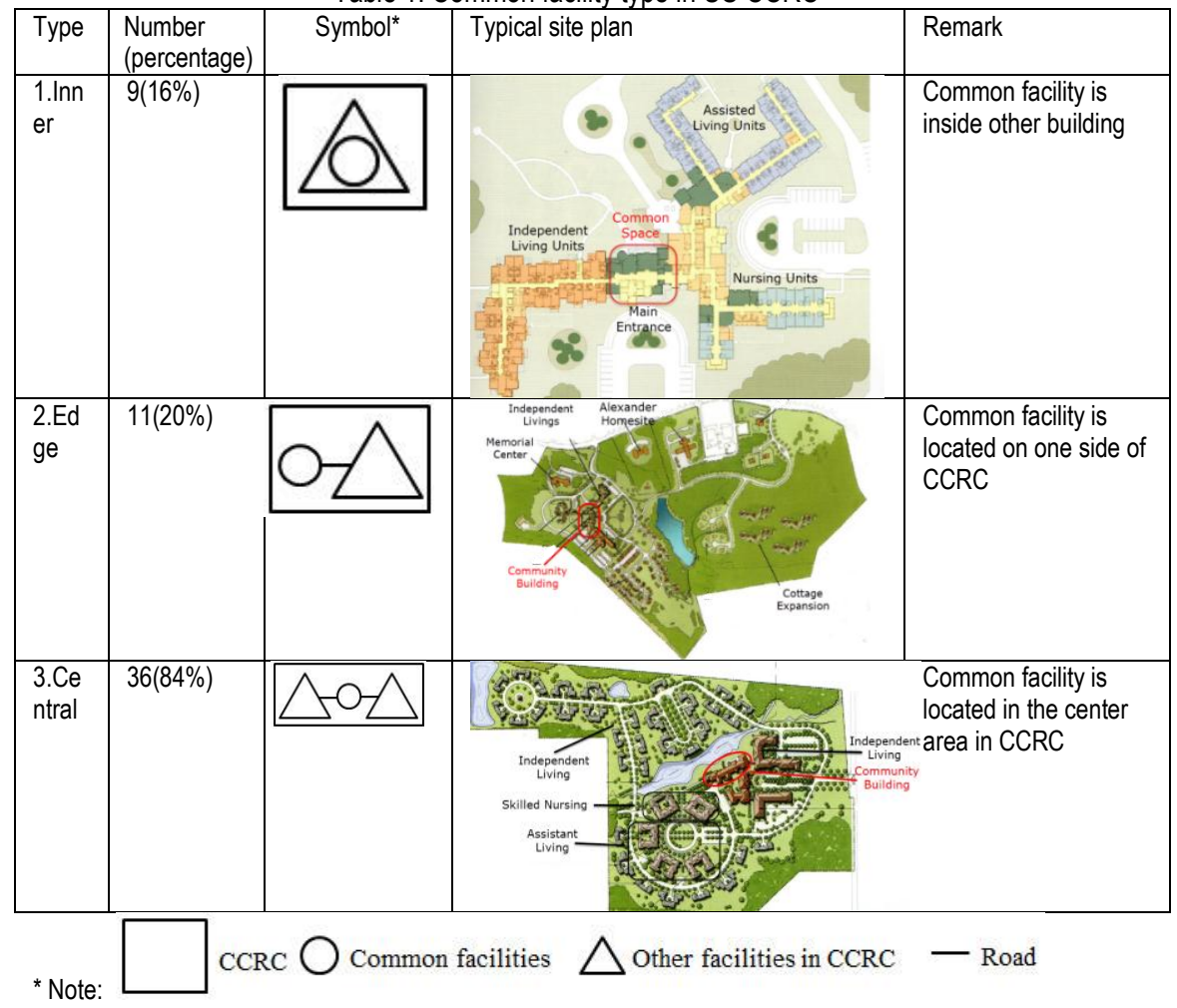

(Source: Created by author)

(1) Number of CCRCs in each type 
The number and percentage of CCRC in each common facility type is presented in Table 1. It tells that central allocation of the common facility is dominant, accounts for $64 \%$ in our investigation.

(2) CCRC common facility type distribution over time

Figure 2 shows the transition of each common facility type since 1990. It can be seen that type 3 (central type) is dominant in the past 25 years.

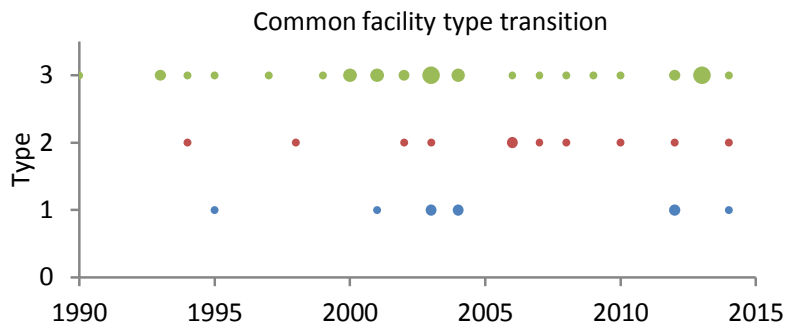

Figure 2: US CCRC common facility transition in recent year(Bubble size represents number of CCRCs)

(Source: Created by author)

\subsection{Evaluation by Average Integration}

(1) Type 1 - Inner type

The integration of common facility and CCRC all space unit average, as well as a comparison between them, is provided in Table 2 .

$\mathrm{T}$ in Table 2 means the integration value of common facility is higher than CCRC all space unit average, $\mathrm{F}$ is opposite. The result of Table 2 indicates that almost all common facilities in this type have greater spatial centrality than CCRC all space units average.

Table 2: Integration result of inner type common facility

\begin{tabular}{ccccc}
\hline Build year & $\begin{array}{c}\text { Number } \\
\text { of CCRC }\end{array}$ & $\begin{array}{c}\text { CCRC } \\
\text { Ave. }\end{array}$ & $\begin{array}{c}\text { C.F. } \\
\text { Ave. }\end{array}$ & $\begin{array}{c}\text { C.F. Ave.> } \\
\text { CCRC Ave }\end{array}$ \\
\hline 1995 & 1 & 0.5675 & 0.5324 & $\mathrm{~F}$ \\
2001 & 1 & 1.0475 & 1.0692 & $\mathrm{~T}$ \\
2003 & 2 & 1.0356 & 1.2176 & $\mathrm{~T}, \mathrm{~T}$ \\
2004 & 2 & 1.1249 & 1.4241 & $\mathrm{~T}, \mathrm{~T}$ \\
2012 & 2 & 1.1148 & 1.2487 & $\mathrm{~T}, \mathrm{~T}$ \\
2014 & 1 & 1.8437 & 2.0873 & $\mathrm{~T}$ \\
\hline Overall mean & 9(total) & 1.1223 & 1.2632 & \\
\hline
\end{tabular}

Notes: C.F. - Common facility

(Source: Created by author)

(2) Type 2 - Edge type

The result is listed in Table 3. There are 7 of 11 CCRCs in which the integration of common 
facility is less than CCRC all space unit average, which indicates the general lower spatial centrality of the common facility in this type of CCRCs.

Table 3: Integration result of edge type common facility

\begin{tabular}{ccccc}
\hline Build year & $\begin{array}{c}\text { Number } \\
\text { of CCRC }\end{array}$ & CCRC Ave. & $\begin{array}{c}\text { C.F. } \\
\text { Ave. }\end{array}$ & $\begin{array}{c}\text { C.F. Ave.> } \\
\text { CCRC Ave. }\end{array}$ \\
\hline 1994 & 1 & 1.0613 & 0.6812 & $\mathrm{~F}$ \\
1998 & 1 & 0.9983 & 0.6013 & $\mathrm{~F}$ \\
2002 & 1 & 1.0014 & 1.0414 & $\mathrm{~T}$ \\
2003 & 1 & 0.6196 & 0.5293 & $\mathrm{~F}$ \\
2006 & 2 & 1.2049 & 1.3415 & $\mathrm{~F}, \mathrm{~T}$ \\
2007 & 1 & 1.0023 & 0.8629 & $\mathrm{~F}$ \\
2008 & 1 & 1.7879 & 1.9483 & $\mathrm{~T}$ \\
2010 & 1 & 0.8502 & 0.7533 & $\mathrm{~F}$ \\
2012 & 1 & 1.0295 & 0.7957 & $\mathrm{~F}$ \\
2014 & 1 & 1.8514 & 2.0472 & $\mathrm{~T}$ \\
\hline Overall mean & 11 (total) & 1.1407 & 1.0602 & \\
\hline \multicolumn{5}{c}{ Notes: C.F. - Common facility } \\
\hline \multicolumn{5}{c}{ (Source: Created by author) }
\end{tabular}

(3) Type 3 - Centre type

The result is shown in Table 4. The integration of common facility in 30 of 36 CCRCs is higher than CCRC all space unit average. It tells that most of the common facilities in this type have greater spatial centrality in the US CCRCs.

Table 4: Integration result of central type common facility

\begin{tabular}{lllll}
\hline Build year & $\begin{array}{l}\text { Number } \\
\text { of CCRC }\end{array}$ & $\begin{array}{l}\text { CCRC } \\
\text { Ave. }\end{array}$ & $\begin{array}{l}\text { C.F. } \\
\text { Ave. }\end{array}$ & $\begin{array}{l}\text { C.F. Ave. } \\
\text { CCRC Ave. }\end{array}$ \\
\hline 1990 & 1 & 1.3211 & 1.2913 & $\mathrm{~F}$ \\
1993 & 2 & 0.8392 & 1.0568 & $\mathrm{~T}, \mathrm{~T}$ \\
1994 & 1 & 1.1487 & 1.4175 & $\mathrm{~T}$ \\
1995 & 1 & 1.2851 & 1.2939 & $\mathrm{~T}$ \\
1997 & 1 & 0.6506 & 0.6071 & $\mathrm{~F}$ \\
1999 & 1 & 0.9493 & 1.0324 & $\mathrm{~T}$ \\
2000 & 3 & 1.1508 & 1.6638 & $\mathrm{~T}, \mathrm{~T}, \mathrm{~T}$ \\
2001 & 3 & 1.0997 & 1.2296 & $\mathrm{~F}, \mathrm{~T}, \mathrm{~T}$ \\
2002 & 2 & 1.1866 & 1.6418 & $\mathrm{~T}, \mathrm{~T}$ \\
2003 & 5 & 1.1276 & 1.3485 & $\mathrm{~T}, \mathrm{~F}, \mathrm{~T}, \mathrm{~T}, \mathrm{~T}$ \\
2004 & 3 & 1.0011 & 1.1962 & $\mathrm{~T}, \mathrm{~T}, \mathrm{~T}$ \\
2006 & 1 & 0.8517 & 1.0864 & $\mathrm{~T}$ \\
2007 & 1 & 1.2389 & 1.8447 & $\mathrm{~T}$ \\
2008 & 1 & 1.1254 & 1.0356 & $\mathrm{~F}$ \\
2009 & 1 & 0.8368 & 1.0302 & $\mathrm{~T}$ \\
2010 & 1 & 0.7721 & 0.9752 & $\mathrm{~T}$ \\
2012 & 2 & 1.2967 & 1.6167 & $\mathrm{~T}, \mathrm{~T}$ \\
2013 & 5 & 1.0946 & 1.3056 & $\mathrm{~T}, \mathrm{~F}, \mathrm{~T}, \mathrm{~T}, \mathrm{~T}$ \\
2014 & 1 & 1.1687 & 1.5187 & $\mathrm{~T}$ \\
\hline Overall mean & 36 (total) & 1.0603 & 1.2733 & \\
\hline \multicolumn{5}{r}{} \\
\hline
\end{tabular}


(4) Overall CCRCs

The integration and trend line for both common facility and CCRC all space unit average are shown in figure 3. This figure discloses that the integration of both common facility and CCRC average was little increased from the year of 1990 to 2015, which means that common facility as a place for holding social activity is getting more spatial centrality in CCRC, and CCRC itself as a place to provide living and care service for elderly, all space unit include residential buildings, service, and administration complexes are getting more spatially integrated in recent years.

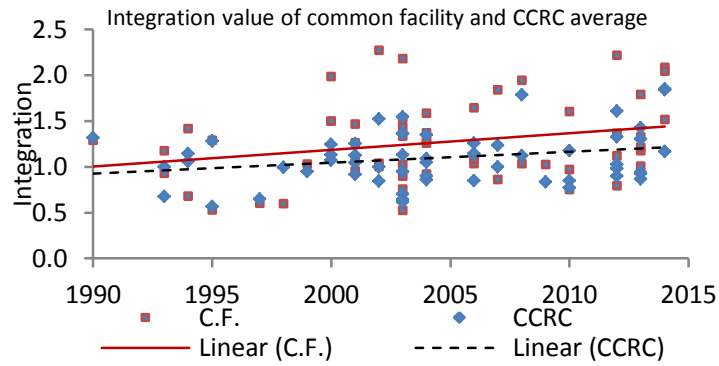

Figure 3: Integration of common facility(C.F.) and CCRC average

(Source: Created by author)

\subsection{Evaluation by Average Connectivity}

The connectivity of CCRC all space unit average and the common facility is displayed in figure 4 . The trend lines in this figure reveal that the connectivity of common facility was slightly increased from the year of 1990 to 2015, which means more connections in common facility in modern US CCRCs.

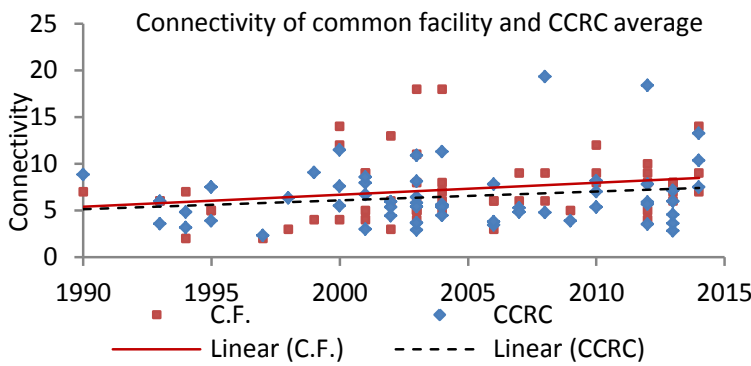

Figure 5: Connectivity of common facility(C.F.) and CCRC average (Source: Created by author)

\subsection{Evaluation by Route Space with Highest Spatial Integration}

(1) Route space integration model 
To find the path by which residents may select often, the route space with the highest integration is analyzed, the result and typical site plan example are presented in Table 5. Based on the result, the CCRCs are defined into six route space integration models.

Table 5: Route space integration model in US CCRC

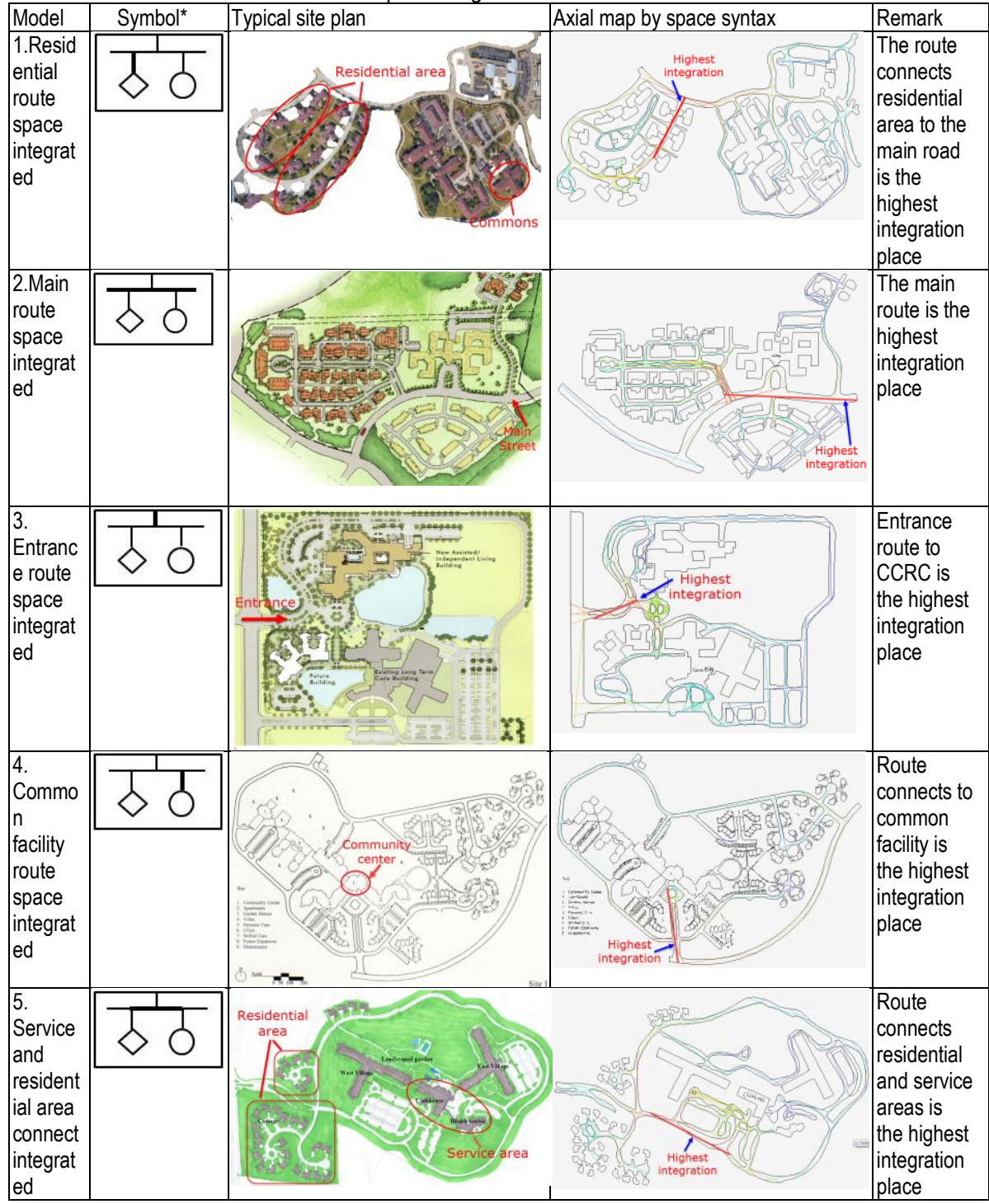


Bai, L. \& Nasu, S. / Asian Journal of Environmen-Behaviour Studies, ajE-Bs, 2(5) Oct / Dec 2017 (p.1-13)

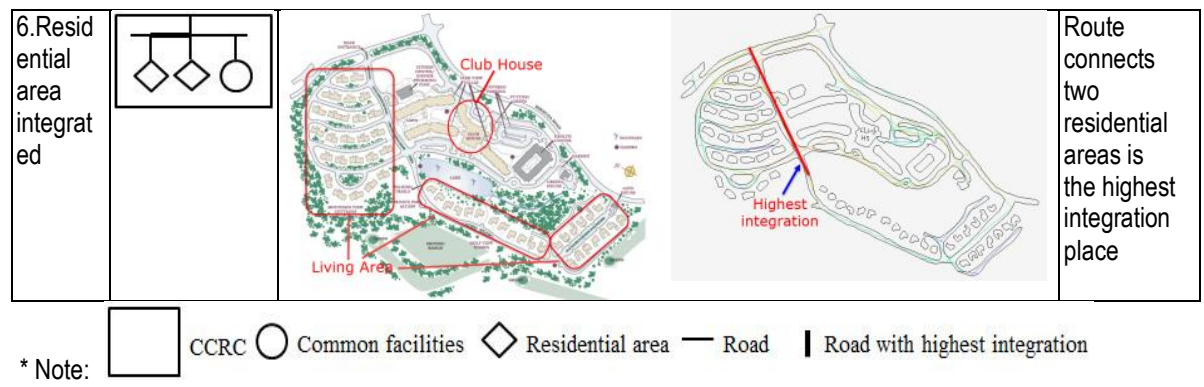

(Source: Created by author)

Model 1- Residential route space integrated. In this model, the route in residential area connects to the main road in CCRC is the highest integration place.

Model 2 - Main route space integrated. In this model, the main road in CCRC is the highest integration place.

Model 3 - Entrance route space integrated. The entrance route to CCRC owns the highest integration.

Model 4 - Common facility route space integrated. The route to a common facility is the highest integration place.

Model 5 - Service and residential area connection route space integrated. In this model, the route connects residential, and service area is the highest integration place.

Model 6 - Residential area route space integrated. The route connects two residential areas is the highest integration place.

(2) Number of CCRCs in each integration model

The result is presented in Figure 5 . Model 4, the common facility route space integrated CCRCs takes the largest proportion, i.e., CCRCs with the route connects to a common facility being the highest integration place is predominant in US CCRCs.
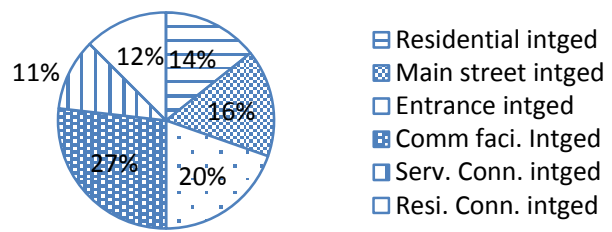

Figure 5: Integration model distribution of US CCRCs (Source: Created by author)

\subsection{Relation between Common Facility Type and Route Space Integration Model}

The relation between common facility type and route space integration model is displayed 
in figure 6. In this figure, the bubble size stands for the number of CCRCs that are consistent with both facility type and integration model.

Besides, based on the order of CCRC number in figure 6, the top 8 combinations of common facility type and space integration model is listed in Table 6.

It can be seen from Table 6 that common facility type 3 with integration model 4 , that is a central area common facility with the route to the common facility being the highest integration place takes the largest number of CCRCs in the US today. The second popular spatial design is central area common facility allocation with the entrance route to CCRC is the highest place, which counts for $13 \%$. The $3^{\text {rd }}$ and fourth popular spatial design are central area common facility allocation with the main route or route connect two residential areas being the highest integration place, both of them count for $8.9 \%$.

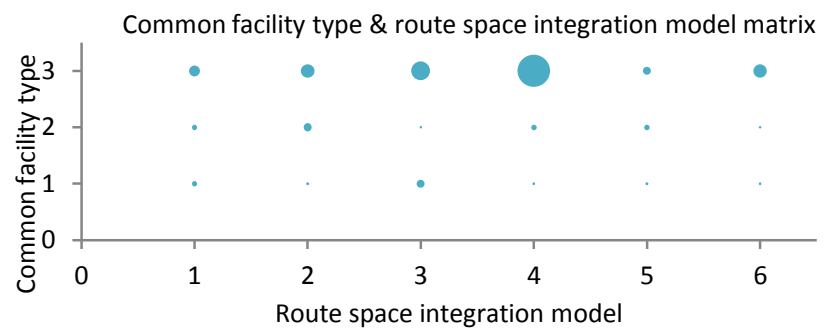

Figure 6: Common facility type and route space integration model (Bubble size represents number of CCRCs)

(Source: Created by author)

Table 6: US CCRC spatial structure modes

\begin{tabular}{|c|c|c|c|c|}
\hline Rank & Occurrence & Percentage, $\%$ & C.F.type & Highest integration route space \\
\hline 1 & 12 & 21 & Central & Route connects to common facility \\
\hline 2 & 7 & 13 & Central & Entrance route to CCRC \\
\hline 3 & 5 & 8.9 & Central & Main route in CCRC \\
\hline 4 & 5 & 8.9 & Central & Route connects two residential areas \\
\hline 5 & 4 & 7.1 & Central & $\begin{array}{l}\text { Route connects residential area to the } \\
\text { main road }\end{array}$ \\
\hline 6 & 3 & 5.4 & Central & $\begin{array}{l}\text { Route connects residential and service } \\
\text { area }\end{array}$ \\
\hline 7 & 3 & 5.4 & Inner & Entrance route to CCRC \\
\hline 8 & 3 & 5.4 & Edge & Main road in CCRC \\
\hline Others & 14 & 25 & & \\
\hline
\end{tabular}

\subsection{Conclusions}

Based on geological allocation three common facility types in US CCRCs are defined, they are inner, edge and central common facility types. Among them, the central area common 
facility is predominant. It accounts for $64 \%$ in our investigation.

The calculation of spatial characteristics of integration and connectivity of common facility and CCRCs discloses that spatial integration of both common facility and CCRC all space unit average were in the uptrend from the year of 1990 to 2015.

Based on the route space with highest integration value, six route space integration models are defined. Within which, the CCRC with route connects to a common facility being the highest integration place is most widespread.

The combination of common facility allocation type and most integrated route space reveals the fashion of common facility in US CCRCs today. With the accelerating aged society worldwide, the result of common facility spatial structure fashion in US CCRC in this article is expected to be a reference for common space designing in other countries such as Japanese version of CCRC which is expected to spread across all Japan soon.

The conclusion in this article is based on Space Syntax theory, the theory provides a view of spatial layout but ignores some practical aspects in the real world like space size, decorations, and attractions. This study will be improved by including common facility space size in next phase.

\section{Acknowledgements}

This study is partly subsidized by Tokyo Institute of Technology TRA program, data, and conclusion in this article will be part of author's Ph.D. dissertation.

\section{References}

AIA Design for Aging Knowledge Community. (2014) Design for Aging Review 12th edition. Australia: The Images Publishing Group Pty Ltd.

Ayalon, A. (2012) Social ties in the context of the continuing care retirement community. Qualitative Health Research, 23(3), 396-406.

Behbahani, P. (2014) Comparing the properties of different space syntax techniques for analyzing interiors, 48th international conference of the Architectural Science Association, 683-694.

Brown, E. (1986) Continuity and change in the urban house. Comparative Studies in Society and History, 28(3),558590.

Dettlaff, Weronika(2014) Space Syntax Analysis - Methodology of Understanding the Space, Ph.D. Interdisciplinary Journal, p.283-291

Fujii, S. (2015) Current US CCRC Status and the possibility to develop in Japan,3, 57-66.

Hillier B. (1996) Space is a machine, Cambridge University Press, p.246. 
Bai, L. \& Nasu, S. / Asian Journal of Environmen-Behaviour Studies, ajE-Bs, 2(5) Oct / Dec 2017 (p.1-13)

Joseph, A. and Zimring C. (2007) Where Active Older Adults Walk, Environment and Behavior, 39(1), 75-105.

Lois J. et al. (2006) Assessing and comparing physical environments for nursing home residents: using new tools for greater research specificity, Gerontologist, 46(1), $42-51$.

Marakami, S. (2011) The relation between environment and living in nursing home, Proceedings of Architecture Institute of Japan, E-1.Architectural Planning I.

Mitsubishi Research Institute (2015) Sustainable Platinum - Community(Japanese Version of CCRC) Policy Advice.

Schafer, M. (2015) On the locality of asymmetric close relations: Spatial proximity and health differences in a senior community. Journals of Gerontology, Series B: Psychological Sciences and Social Sciences, 70(1), 100-110.

Space Group UCL/DepthMap (2014), https:/github.com/SpaceGroupUCL/DepthMap/tree/master/DepthMap [Access Jan. 10, 2017]

Sugihara, S. (2000) Place Attachment and Social Support at Continuing Care Retirement Communities. Environment and Behavior.

Turner A., Hillier B. (2005) An algorithmic definition of the axial map. Environment and Planning B: Planning and Design. 32,425-444.

Yang, B. (2012) Place Meaning: Aging in place and senior housing an interpretation on space design of Sung-Lien social welfare Park, Taiwan. Times Architecture, 6, 59-64. 